\title{
Use of a Right Ventricular Continuous Flow Pump to Validate the Distensible Model of the Pulmonary Vasculature
}

\author{
F. VANDEN EYNDEN ${ }^{1,3}$, P. SEGERS ${ }^{2}$, T. BOVÉ ${ }^{3}$, F. DE SOMER ${ }^{3}$, B. EL OUMEIRI ${ }^{1}$, \\ G. VAN NOOTEN ${ }^{1,3}$
}

${ }^{1}$ Department of Cardiac Surgery, Université Libre de Bruxelles, Hopital Académique, Erasme, Brussels, Belgium, ${ }^{2}$ IBiTech-bioMMeda, Ghent University, Belgium, ${ }^{3}$ Laboratory of Experimental Cardiac Surgery, Ghent University Hospital, Belgium

Received February 21, 2018

Accepted November 13, 2018

Epub Ahead of Print January 10, 2019

\section{Summary}

In the pulmonary circulation, resistive and compliant properties overlap in the same vessels. Resistance varies nonlinearly with pressure and flow; this relationship is driven by the elastic properties of the vessels. Linehan et al. (1982) correlated the mean pulmonary arterial pressure and mean flow with resistance using an original equation incorporating the distensibility of the pulmonary arteries. The goal of this study was to validate this equation in an in vivo porcine model. In vivo measurements were acquired in 6 pigs. The distensibility coefficient (DC) was measured by placing piezo-electric crystals around the pulmonary artery (PA). In addition to experiments under pulsatile conditions, a right ventricular (RV) bypass system was used to induce a continuous pulmonary flow state. The Linehan's equation was then used to predict the pressure from the flow under continuous flow conditions. The diameter-derived DC was $2.4 \% / \mathrm{mmHg}$ $( \pm 0.4 \%)$, whereas the surface area-based DC was $4.1 \% / \mathrm{mmHg}$ $( \pm 0.1 \%)$. An increase in continuous flow was associated with a constant decrease in resistance, which correlated with the diameter-based $D C(r=-0.8407, p=0.044)$ and the surface areabased DC $(r=-0.8986, p=0.028)$. In contrast to the Linehan's equation, our results showed constant or even decreasing pressure as flow increased. Using a model of continuous pulmonary flow induced by an RV assist system, pulmonary pressure could not be predicted based on the flow using the Linehan's equation. Measurements of distensibility based on the diameter of the PA were inversely correlated with the resistance.

\section{Key words}

Pulmonary circulation • Distensibility • Assist device • Vascular resistence

\section{Corresponding author}

F. Vanden Eynden, Department of Cardiac Surgery, 808 Route de Lennick, B-1070 Brussels, Belgium. E-mail: frederic.vanden.eynden@erasme.ulb.ac.be

\section{Introduction}

In the pulmonary circulation, resistance is usually considered to be the ratio of the driving pressure (mean pulmonary arterial pressure [MPAP] minus the left atrial pressure [LAP]) to the flow. However, the observed measurements are not consistent with the predicted values (Naeije 2003). Indeed, the relationship is curvilinear instead of linear, and the intercept is higher than the outflow pressure. One explanation is that there is a critical opening pressure for the vessels and that some vessels may be recruited according to the need (i.e. a so-called Starling resistor) (Permutt and Riley 1963). However the mean pressure/mean flow relationship is not optimally predicted by sequential vessel opening (Mitzner 1983); thus, other hypotheses have been proposed to explain the observed relationships.

One hypothesis is based on the distensibility properties of the resistive vessels. In the pulmonary circulation, there is an overlap of compliance and resistive features within the same vessels, and these compliance properties have been observed to extend down to the capillary level (al-Tinawi et al. 1991, Presson et al. 1998). Such a design has been shown to be optimal for the homogenous distribution of flow in the lung 
vasculature (Dawson et al. 1999a).

In practice, if resistance vessels exhibit distensibility properties, as pressure increases, vascular resistance is expected to decrease.

Krenz and Dawson (2002) and Linehan et al. (1992) have thoroughly investigated this question and developed an equation linking the pulmonary arterial pressure $(\mathrm{P})$ to the flow $(\mathrm{Q})$ through unrelated variables:

$$
P=\frac{\left[(1+\alpha \cdot L A P)^{5}+5 \cdot \alpha \cdot R_{0} \cdot Q\right]^{\frac{1}{5}}-1}{\alpha}
$$

where $\mathrm{R}_{0}$ is the resistance at zero flow, a mathematical abstraction translating the maximal resistance of the vascular tree based on its morphology, LAP is the left atrial pressure; and alpha $(\alpha)$ is the distensibility coefficient $\left(\mathrm{DC}_{\alpha}\right)$, which reflects the elastic properties of the vessels. This mathematical expression describes a weakly nonlinear relationship between pressure and flow, with higher distensibility leading to a lower increase in pressure for any given flow.

A potential use for this equation could be to compare patients based on the value of their resistance at zero flow $\left(\mathrm{R}_{0}\right)$, thereby reflecting the true resistivity of the pulmonary circulation that is unrelated to the distension pressure. However, determination of $R_{0}$ requires knowing the value of the distensibility coefficient, which has not been determined under pathological conditions.

One way to derive the distensibility coefficient is to make some assumptions about $\mathrm{R}_{0}$, which is sometimes reported as the resistance at rest (Malhotra et al. 2016) rather than the resistance at zero pressure. Several studies have used dobutamine and exercise to obtain pressure and flow relationships that could be fitted with the Linehan's equation to obtain the $\mathrm{DC}_{\alpha}$ (Reeves 2005).

Although the Linehan's equation is used in the clinical setting (Wauters et al. 2015), its reliability has been poorly explored. The initial equation was designed in the lower lobe of the lung, exclusively in zone 3 of West, and whether the equation applies to the whole lung has never been validated.

The goal of this study was to validate the Linehan's equation in an in vivo experimental model wherein the pulmonary system functions in its physiological environment, but the pulmonary flow is tightly controlled by a continuous flow system bypassing the right ventricle. We also compared the $\mathrm{DC}_{\alpha}$ as defined by Linehan et al. (1992) which requires measurements at zero pressure, with the DC derived using diastolicsystolic cross-sectional area variation $\left(\mathrm{DC}_{\mathrm{A}}\right)$, which can be determined non-invasively.

\section{Materials and Methods}

The study protocol was performed according to the standards of "The Guide for the Care and Use of Laboratory Animals" published by the National Institutes of Health (publication 85-23, revised 1996) and approved by the ethical committee for animal research of the Ghent University Hospital (ECD 18/30).

\section{Experimental preparation}

Six landrace pigs (weight: $50.6 \pm 4.2 \mathrm{~kg}$ ) were included in the study. Following premedication with intramuscular tiletamine and zolazepam in a combined solution with $2 \%$ xylazine $(0.2 \mathrm{ml} / \mathrm{kg})$, anesthesia was induced with intravenous propofol $(3 \mathrm{mg} / \mathrm{kg})$, sufentanil $(0.005 \mathrm{mg} / \mathrm{kg})$ and rocuronium bromide $(1 \mathrm{mg} / \mathrm{kg})$. After endotracheal intubation, the animals were mechanically ventilated with $\mathrm{FiO}_{2}(40 \%)$ and tidal volumes of $0.1-0.15 \mathrm{l} / \mathrm{kg}$. Anesthesia was maintained with continuous sevoflurane $(2.5 \%)$ administered through the AnaConda ${ }^{\circledR}$ system (Sedana Medical, Sundbyberg, Sweden), additional boluses of sufentanil $(0.005 \mathrm{mg} / \mathrm{kg})$ were administered as needed. Basic monitoring included electrocardiography, body temperature measurement and capnography. Intermittent arterial blood gas sampling was performed to control the ventilatory settings.

A central venous line was inserted via the external jugular vein for saline infusion at a constant rate of $3-5 \mathrm{ml} / \mathrm{kg} / \mathrm{h}$. A single-lumen fluid-filled catheter was placed in the left carotid artery for continuous monitoring of systemic arterial pressure.

The heart was exposed through a midline sternotomy and longitudinal opening of the pericardium. A pressure transducer-tipped catheter (Millar SPR-524, Millar Instruments, Houston, TX) was inserted into the pulmonary artery (PA).

Four 2-mm piezo-electric crystals (Sonometrics, London, Ontario, Canada) were secured with $6 / 0$ prolene stitches to the base of the PA in a two-by-two diametrically opposed pattern to measure the instantaneous PA diameter under pulsatile flow conditions. The diameter of the PA at zero pressure was measured after sacrificing the animals. 

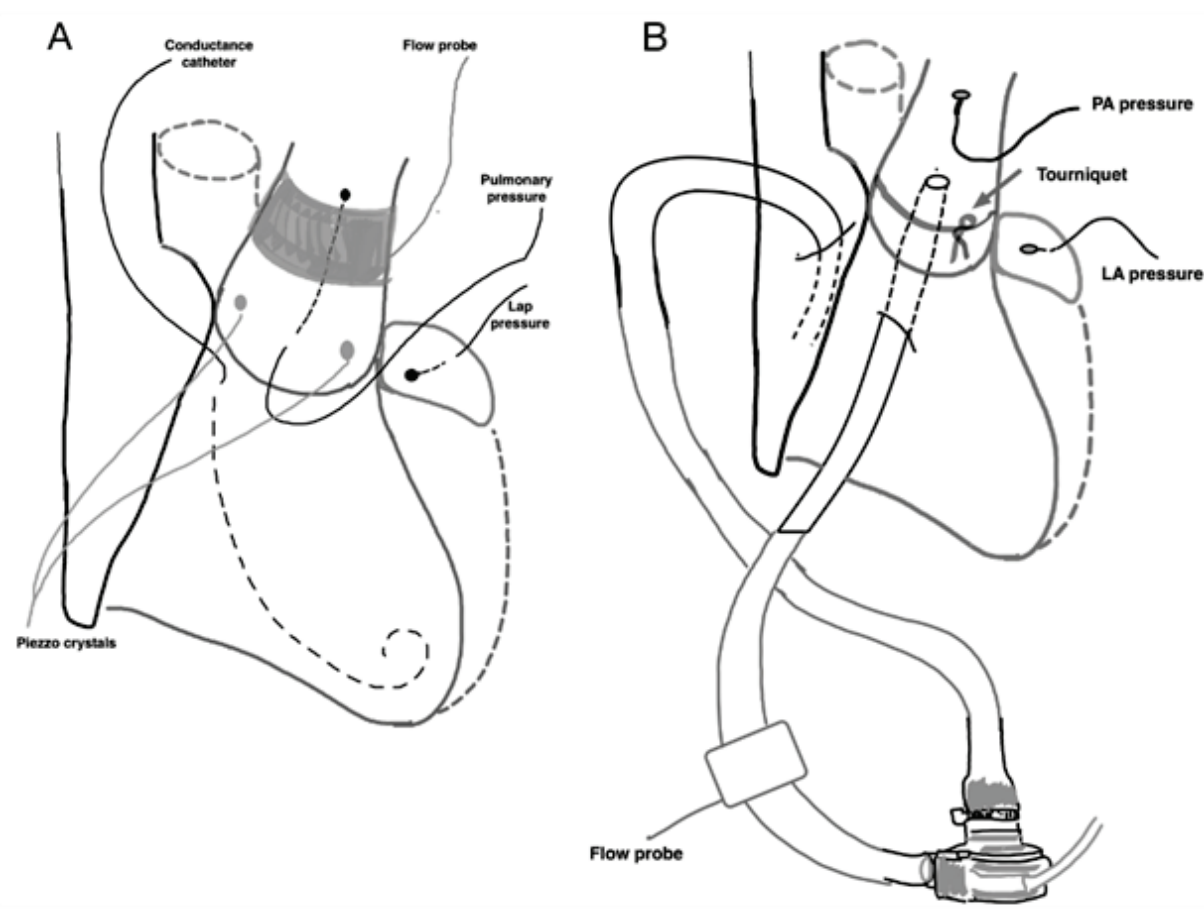

Fig. 1. Experimental settings. A: Pulsatile setting. B: Right ventricular bypass with continuous flow pump.

A 16-mm perivascular flow probe (Transonic Systems, Ithaca, NY, USA) was placed around the PA for continuous measurement of the PA flow. A second pressure transducer-tipped catheter (Millar SPR-524; Millar Instruments, Houston, TX, USA) was inserted into the left atrium to monitor LAP, while a $7 \mathrm{~F}$ dual-field pressure-volume catheter (Millar, Millar Instruments, Houston, TX) was inserted by direct puncture into the right ventricle to monitor intraventricular pressure. The pressure and flow in the PA, LAP and right ventricular (RV) pressure were recorded at the basal level under pulsatile conditions (Fig. 1A).

In the second phase, the PA perivascular flow probe and the piezo-electric crystals were removed. The PA was encircled with umbilical tape as a tourniquet for PA constriction. A 29Fr multiperforated cannula (Stöckert Instruments, München, Germany) was inserted into the right atrium. Simultaneously, a straight $22 \mathrm{Fr}$ cannula (Medtronic Inc., Minneapolis, USA) was inserted into the PA through the RV outflow tract and secured with a $5 / 0$ prolene purse-string suture. The cannulas were connected to a continuous flow pump (Heartware Inc., Miami Lakes, FL, USA) via two silicon tubes (size 31Fr at the inflow side and size $27 \mathrm{Fr}$ at the outflow side, Fig. 1). The pump was initiated at 2000 RPM, and the tourniquet was tied around the PA cannula to limit the PA flow that was delivered by the continuous flow pump. The exact pump flow was recorded via a flow probe Transonic Systems, Ithaca, NY, USA) connected to the
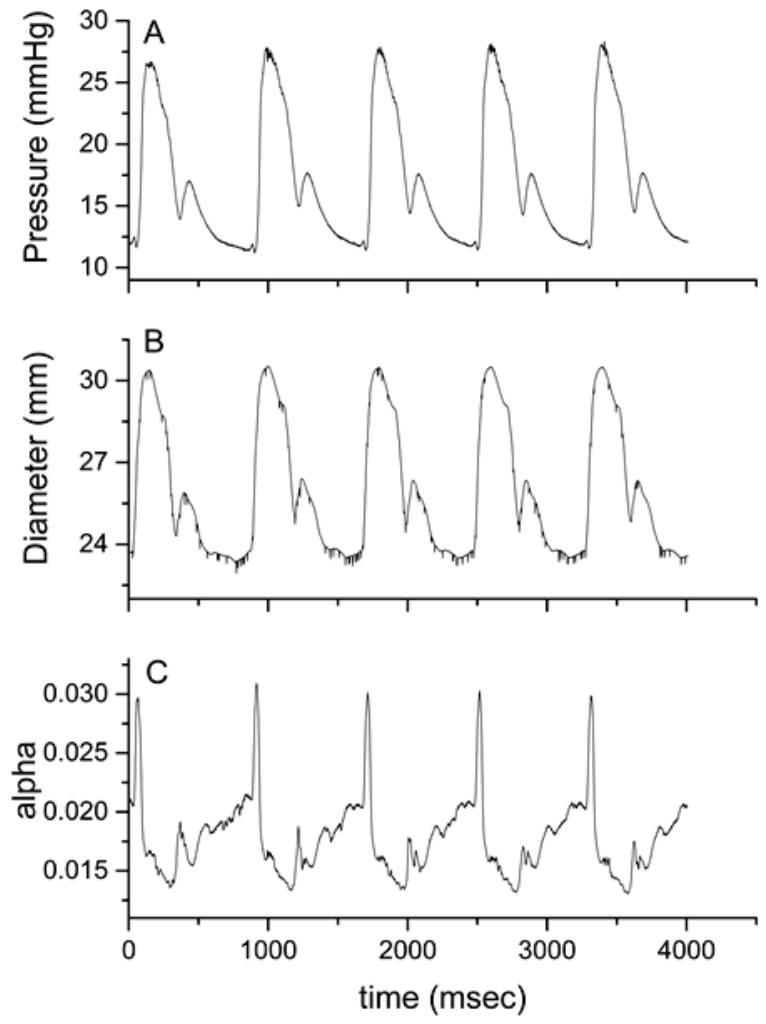

Fig. 2. Pig 1 instantaneous measurements. A: Pulmonary artery pressure. B: Instantaneous diameter. C: instantaneous distensibility coefficient a.

arterial tubing. The pump flow was progressively increased by increments of 100 RPM until the flow doubled (Fig. 1B). 

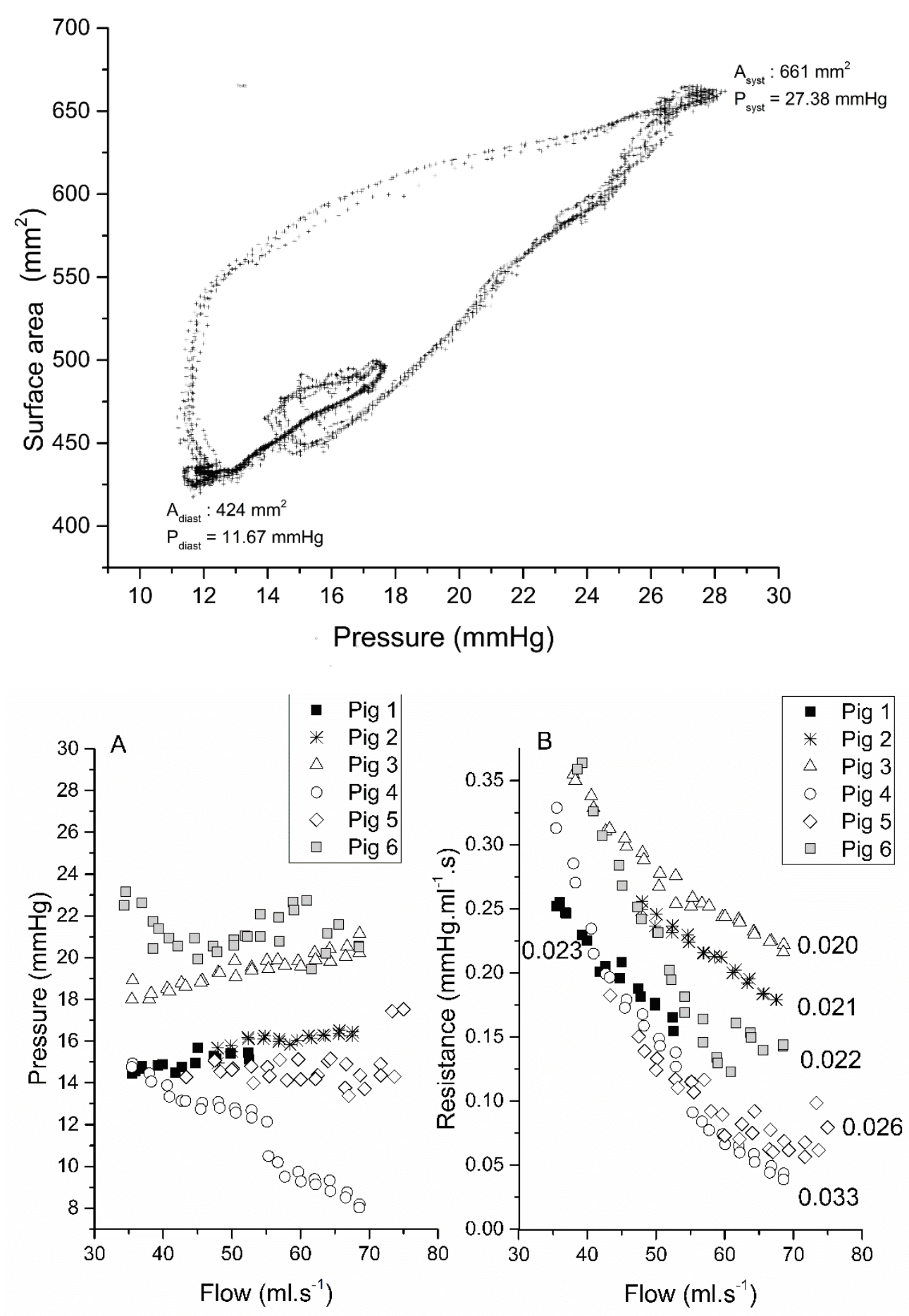

Fig. 3. Pulmonary artery pressure and surface relationship. The surface area distensibility coefficient was measured based on the systolic area $\left(A_{\text {syst }}\right)$, diastolic area $\left(A_{\text {disat }}\right)$ and the pulse pressure $\left(P_{\text {syst }}-P_{\text {diast }}\right)$.

Fig. 4. A: Flow and pressure relationship with increasing pump flow. B: Flow and resistance relationship with increasing pump flow. Distensibility coefficient alpha is indicated for every animal.

\section{Data acquisition and processing}

Pressure, flow, intraventricular volume and PA diameter data were recorded and digitized at $1000 \mathrm{~Hz}$ with a data acquisition system (Powerlab 16/9, Ad Instrument, Dunedin, New Zealand) and software (Labchart 7, Ad Instrument, Dunedin, New Zealand). Data analysis was performed using embedded or custommade functions in a MATLAB environment (MATLAB, Mathworks, Natick, MA).

\section{Validation of the Linehan paradigm}

i) Distensibility

According to Linehan et al. (1982), the diameter of the PA (D) is linearly related to the pressure (P) when normalized to its diameter at zero pressure $\left(\mathrm{D}_{0}\right)$ :

$$
\frac{D}{D_{0}}=1+\alpha P
$$



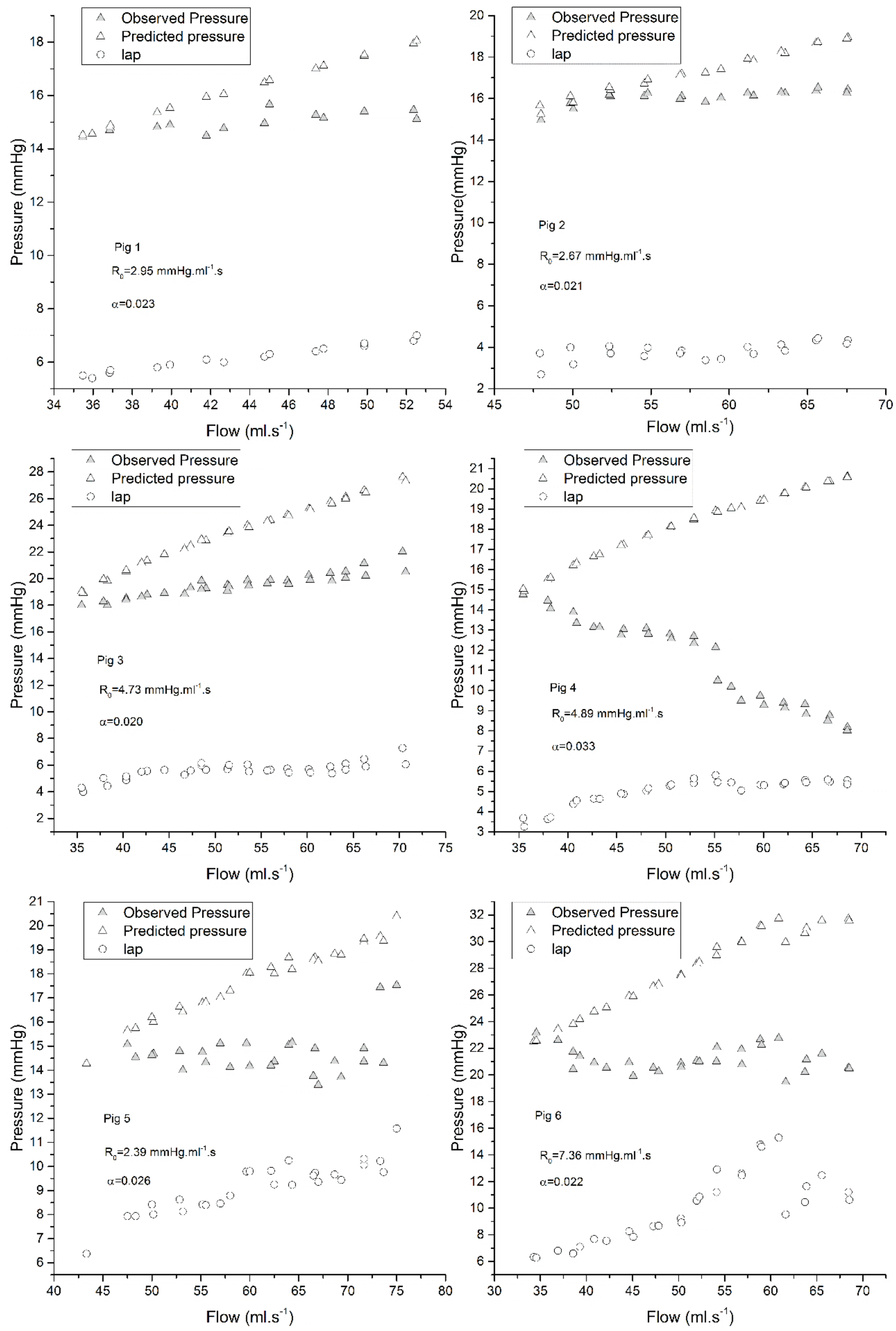

Fig. 5. Measured pressure under continuous flow conditions and the predicted values for pressure according to Linehan's equation. 
Table 1. Distensibility coefficients

\begin{tabular}{llllll}
\hline & MPAP & Mean $\boldsymbol{\alpha}$ & $\min \boldsymbol{\alpha}$ & $\max \boldsymbol{\alpha}$ & $\mathbf{D C}_{\mathbf{A}}$ \\
\hline Pig 1 & 13.4 & 0.023 & 0.009 & 0.027 & 0.041 \\
Pig 2 & 21.1 & 0.021 & 0.016 & 0.037 & 0.042 \\
Pig 3 & 14.9 & 0.020 & 0.010 & 0.023 & 0.040 \\
Pig 4 & 11.8 & 0.033 & 0.023 & 0.060 & 0.042 \\
Pig 5 & 15.1 & 0.026 & 0.018 & 0.033 & 0.044 \\
Pig 6 & 14.1 & 0.022 & 0.018 & 0.031 & 0.040 \\
\hline
\end{tabular}

Distensibility coefficients (DC); MPAP: Mean pulmonary artery pressure in $\mathrm{mmHg}$; $\mathrm{DC}_{\alpha}$ presented with mean, minimum and maximum value in $\% / \mathrm{mmHg}$. Area based distensibility coefficient.

The coefficient $\alpha$ was calculated for five coupled pressure-diameter cycles under pulsatile flow conditions (Fig. 2) while the animal was disconnected from the ventilator.

Two perpendicular diameters at zero pressure were measured after the animals were sacrificed, and the PA was harvested to obtain $\mathrm{D}_{0}$. A ring of a height of 0.5 to $1 \mathrm{~cm}$ was cut at approximately $1 \mathrm{~cm}$ from the pulmonary valve, and the diameter was immediately measured ex vivo.

Another distensibility coefficient was measured: the area-based $\mathrm{DC}\left(\mathrm{DC}_{\mathrm{A}}\right)$, which is defined as

$$
\mathrm{DC}_{\mathrm{A}}=\frac{\frac{(\text { Asyst-Adiast })}{\text { Adiast }}}{\text { pulse pressure }}
$$

where $\mathrm{A}_{\text {syst }}$ and $\mathrm{A}_{\text {diast }}$ are the cross-sectional areas of the PA in systole and diastole, respectively, and the pulse pressure is the systolic-diastolic pressure difference. Areas were calculated from both orthogonal diameters using the equation of an ellipse ( $\pi^{*}$ vertical diameter $/ 2 *$ horizontal diameter $/ 2$ ). Pressure-surface area curves were plotted to identify the highest and lowest pressures and their corresponding diameters (Fig. 3), and the $\mathrm{DC}_{\mathrm{A}}$ was calculated for each animal concomitant with $\mathrm{DC}_{\alpha}$.

\section{ii) Pressure-flow relationship}

Pressure was measured for different flows under the continuous flow condition. Flow was controlled by changing the RPM of the pump, starting at 1800 RPM; the concomitant resistance was measured (pressureLAP/mean flow) and compared to the distensibility coefficient.

\section{iii) Validation of the Linehan equation}

After determining $\mathrm{DC}_{\alpha}$, we could further assess the validity of equation (1). The values obtained in vivo for the pressure, LAP, hematocrit and flow were used to obtain $\mathrm{R}_{0}$ under continuous flow conditions at the lowest value of flow achievable with the pump (1800 RPM). This value was used to predict the pressure-flow relationship and was compared to the measured pressure.

\section{Statistics}

Correlation analysis was performed using Spearman's correlation. The test results were considered statistically significant at $\mathrm{p}<0.05$.

\section{Results}

Pulmonary arterial compliance in pulsatile flow

Table 1 reports the values of $\mathrm{DC}_{\alpha}$ under pulsatile flow conditions according to the Linehan et al. (1992) definition as well as the values of $\mathrm{DC}_{\mathrm{A}}$.

The correlation between the two DC values was poor $(\mathrm{rho}=0.4816, \mathrm{p}=0.334)$.

\section{Pressure-flow relationship}

Figure 4A shows the pump rate-to-pressure relationship. In 2 out of 6 animals, the pressure remained constant (the slope of the linear fit was zero for pigs 5 and 6). The pressure slightly rose in 3 pigs as the pump rate increased (pigs 1,2 and 3: maximum slope under 0.002). One animal exhibited a clear pressure decrease as the pump rate increased (pig 4: slope of -0.004).

Figure 4B shows the relationship between flow and resistance, indicating that resistance decreases with increasing flow. The different curves are related to $\mathrm{DC}_{\alpha}$. Furthermore, the resistance at $52 \mathrm{ml} / \mathrm{sec}$ (the highest common flow achieved) correlated with $\mathrm{DC}_{\alpha}$. Correlation 
analysis revealed a statistically significant inverse relationship with a Spearman's rho coefficient of -0.8407 $(p=0.044)$. The same analysis was performed with $\mathrm{DC}_{\mathrm{A}}$, yielding a Spearman's rho coefficient of -0.8986 $(\mathrm{p}=0.028)$.

\section{The Linehan's equation}

Figure 5 presents the pressure-flow relationship determined in the different animals. $\mathrm{R}_{0}$ was calculated based on the lowest flow, and this value was used to predict the pressure-flow relationship as flow increased. This semi-quantitative method illustrated the discrepancies between the predicted values and observed values in the animal with the lowest $\mathrm{DC}_{\alpha}$ (pig 3) and the animal with the highest $\mathrm{DC}_{\alpha}$ (pig 4).

\section{Discussion}

The Linehan's equation relates flow and pressure in the pulmonary arterial system through independent variables, including the $\mathrm{DC}_{\alpha}$ of the pulmonary vessel, the resistance at zero flow and the outflow pressure. In this experimental study, we attempted to validate this equation by more precisely measuring the $\mathrm{DC}_{\alpha}$ and by comparing the theoretical pressure-flow relationship with the observed pressureflow relationship. The novelty of our methodology was that the flow was completely controlled by inducing a continuous flow state using an RV bypass system injecting blood in both lungs with an independently functioning left heart. The result showed that the observed and predicted pressures were different.

\section{The Linehan's equation}

Linehan et al. (1982) aimed to establish an equation linking flow to pressure while reflecting the non-linearity of the relationship and its dependence on the hematocrit.

This Linehan's equation was developed as an alternative model of the pressure-flow relationship that is neither an ohmic relationship nor a Starling resistor relationship reflecting sequential opening of the vessels (waterfall model), as these models failed to predict the exact pressure-flow relationship. The model proposed by Linehan et al. (1982) was based on a property of the pulmonary vessels in which both compliant and resistive features are present down to the capillary vessels. Such a system implies that resistance decreases with increased flow proportionally to the distensibility of the vessel, which has been shown to be optimal for homogenous distribution of the flow (Dawson et al. 1999b, Krenz and Dawson 2002).

Linehan et al. (1982) used a tightly controlled model to obtain their equation. Rigid cannulas permitted the control of the inflow and outflow of an isolated left lower lobe of a dog's lung, and measurements were taken at end-expiration, ensuring that outflow pressure was tightly controlled and fixed at $2 \mathrm{mmHg}$. While such a model was optimal to explore the effect of hematocrit changes on the pressure-flow relationship, which was the initial purpose of the original study, the model poorly reflects the physiological conditions in the lung vasculature. As Linehan et al. (1992), his model will reveal the robustness of the parameters under various experimental conditions. To the best of our knowledge, testing the different parameters has not been done, but the equation was nonetheless used in the clinical setting.

To validate the equation, we used a model of whole lung perfusion in an in vivo setting. The exact values of $\mathrm{DC}_{\alpha}$, the hematocrit, pressure, flow and LAP were measured in every animal, and the equation described by Linehan et al. (1992) was reduced to an equation with only one remaining unknown value: the resistance at zero flow $\left(\mathrm{R}_{0}\right)$.

Using our experimental setup with a continuous pump flow, $\mathrm{R}_{0}$ was calculated for the lowest flow, and then, the pressure change per flow increment was computed, with adjustment for the measured LAP while assuming that both the $\mathrm{DC}_{\alpha}$ and hematocrit remained constant. No overlap between the measured values and the predicted values was observed. In all animals, the equation predicted an increase in pressure, whereas the observed pressure was constant.

Discrepancies between the observed and predicted measurements were not surprising since Linehan et al. (1982) specifically developed their equation in zone 3 of West and recognized that in zone 2 of West, the outflow pressure would be the closing pressure (West 1977), which is commonly discussed in a Starling resistor and accounts for recruitability (Mélot et al. 1995). Hence, the actual situation is probably an overlap between distensible vessels and opening pressures, thus explaining the absence of an observed pressure increase with flow increase.

Another significant difference among Linehan's group experiment, our experiment and the physiological condition is that continuous flow equalizes pressure among all the compartments of the vascular tree, 
exploiting the distensible properties of arteries, capillaries and veins, whereas under pulsatile conditions, inertia induces a heterogeneous distribution of the stroke volume with arterial loading that is redistributed during diastole, thus preventing the exposure of capillaries to excessive pressure. Under artificial continuous flow conditions, pressure and flow are uniformly distributed, which may explain our observation of a constant pressure value despite flow increase. The pressure-flow relationship should be further explored, as assist devices that are used to support the right ventricle are constant flow devices and may have an effect on capillary structure when they are used long term (Sezai et al. 1999).

Our inability to reproduce Linehan's group prediction in our observed pressure-flow model leads to questions regarding the premise and formulation of the Linehan's equation. The first question is regarding the nature of the pulmonary circulation, which should not be viewed as either an exclusively distensible system or an exclusively recruitable system but possesses both properties. The other question refers to the formulation of the equation; while the equation may be pertinent to the lower lobe in zone 3 of West, the coefficients may be different in other zones.

One should be aware of the limitations of Linehan's group equation before applying it in the clinical setting. Studies have used the equation to report differences in distensibility between men and women (Argiento et al. 2012), loss of distensibility as an early marker of pulmonary vascular disease (Lau et al. 2016) and lower distensibility in patients with heart failure (Malhotra et al. 2016). To draw their conclusions, these studies have made questionable assumptions: they have used either dobutamine or exertion to increase cardiac output and used the resting cardiac output as $\mathrm{R}_{0}$. The distensibility coefficient was obtained using an iterative approach with the least-squares method (Reeves 2005). One important feature of the equation that is eluded by the assumption made on $\mathrm{R}_{0}$ in these studies is that all the variables are independent of each other and that there is no scale effect. Avoiding scale influence is possible by computing $\mathrm{R}_{0}$ at zero flow, when resistance is normalized. However, when the $\mathrm{R}_{0}$ is approximated by the resistance at resting cardiac output, it is not normalized, and the body surface area (BSA, that takes into account height and weight) may influence the results and the conclusions. For example, women have a lower BSA than men on average; therefore, $\mathrm{R}_{0}$ will be higher in women since pressure at rest is the same despite a lower cardiac output and distensibility will be biased toward higher values.

\section{Distensibility coefficient}

The $\mathrm{DC}_{\alpha}$, which relates the diameter to pressure, is physiologically remarkable because the value of $0.02 \% / \mathrm{mmHg}$ appears to be constant among species (Krenz and Dawson 2003).

Moreover, this coefficient is clinically appealing because it is presumably constant down to the arterioles in a normal pulmonary circulatory system (Presson et al. 1998), at least under normal physiological conditions in healthy specimens.

Linehan et al. (1982) used $\mathrm{DC}_{\alpha}$ to reflect the "lumped distensibility of those vessels that contribute substantially to the vascular resistance". Although some values of $\mathrm{DC}_{\alpha}$ in the major trunk of the pulmonary arteries have been reported in the literature (Hervé et al. 1989) (with some reserve on the pressure measurement at zero flow), most of the values were measured in more distal arteries (Greenwald et al. 1982). While more proximal arteries are larger, less resistive and less affected by the relationship of resistance to distensibility (increasing the diameter will not significantly decrease the resistance, which is already low), they are more accessible for non-invasive assessment; hence, it would be valuable to confirm that the constant distensibility observed from arterioles to capillaries extends to more proximal arteries, including the pulmonary trunk. To the best of our knowledge, this study was the first to include an instantaneous measurement of the $\mathrm{DC}_{\alpha}$. The mean value of $\mathrm{DC}_{\alpha}$ was approximately $0.02 / \mathrm{mmHg}$. The coefficient exceeded $0.03 / \mathrm{mmHg}$ in only one animal, and that animal showed even higher fluctuations, with a maximum coefficient of $0.06 / \mathrm{mmHg}$.

The value of $0.02 / \mathrm{mmHg}$ is also the value reported for the distal arteries (Greenwald et al. 1982) and we could advance that our measurement is a good argument in favor ofa homogeneous distribution of distensibility, from the pulmonary trunk to capillaries. But to prove the concept, a simultaneous measurement in proximal and more distal vessels should be done which, our best knowledge, has never been done. Moreover, we made the assumption that the relation between the distensibility that we measured and the distensibility in the vessels for which the Linehan's group equation was designed, are linearly related. This has not been proved and it is a main limitation of our study. If the compliant properties of the proximal 
vessels and intermediate vessels are different, it could explain the discrepancies with the predicted model that we observed.

Beyond the context of the Linehan's equation, a proper measure of pulmonary vascular distensibility is interesting because the elastic properties of the lung vasculature may exert a strong clinical impact on diseases involving pulmonary arterial hypertension (Tan et al. 2014, Schäfer et al. 2016).

However, measuring the $\mathrm{DC}_{\alpha}$ is controversial, as it requires measuring the vessel diameter at zero pressure, which is nearly impossible in the clinical setting. The methodological requirements to obtain exact $\mathrm{DC}_{\alpha}$ values explain why $\mathrm{DC}_{\alpha}$ values are not reported in the literature for pathological states. Additionally, we have stressed the limitation of $\mathrm{DC}_{\alpha}$ obtained with assumptions regarding $\mathrm{R}_{0}$ in the setting of the Linehan's equation.

The aforementioned disadvantages underlie the need to use other vascular stiffness indices. One of these indices, the $\mathrm{DC}_{\mathrm{A}}$, which we measured in our study, is based on the area change between systole and diastole and has gained widespread acceptance, at least for evaluation of the systemic circulation (Cavalcante et al. 2011).

In the pulmonary circulation, $\mathrm{DC}_{\mathrm{A}}$ has been measured in patients without pulmonary hypertension and has been reported to have a value of $3.1 \% / \mathrm{mmHg}$ (range 2 to $4.1 \%$ ) (Sanz et al. 2009). $\mathrm{DC}_{\mathrm{A}}$ decreases in patients with pulmonary hypertension and this decrease has a negative impact on ventricular function (Stevens et al. 2012). In our study, the $\mathrm{DC}_{\mathrm{A}}$ was fairly constant for all animals (mean: $4.15 \pm 0.16 \%$ ), and a correlation was observed between the $\mathrm{DC}_{\alpha}$ and the decrease in resistance with increased flow.

We compared the two DCs and observed a poor correlation, but the study used a limited number of animals and is underpowered to compare the two indices.

Use of the $\mathrm{DC}_{\alpha}$ is appealing because it appears to remain constant across many species and throughout the lung independent of pressure, but our observations suggest that $\mathrm{DC}_{\mathrm{A}}$ may share the same properties as $\mathrm{DC}_{\alpha}$ in terms of its consistency among species (at least in pigs and humans) and that it has the advantage of being measurable in clinical settings. Therefore, measuring the $\mathrm{DC}_{\mathrm{A}}$ may be more appropriate, as it can be achieved non-invasively.

\section{Conclusions}

This experiment, which used a continuous pulmonary flow model, was designed to verify Linehan's equation, which links pressure to resistance and flow via a distensibility coefficient based on diameter and pressure variations relative to the diameter at zero pressure. The Linehan's equation is valuable for the calculation of resistance at zero flow, which reflects geometrical properties of the vascular tree and could help in the diagnosis of pulmonary vascular diseases, but we did not observe the predicted values. Other formulas of the pressure-flow relationship should thus be developed using distensibility coefficients based on surface variation and pulse pressure, which can be measured in the clinic with modern imaging techniques.

\section{Conflict of Interest}

The authors report that no potential conflicts of interest exist with any companies/organizations whose products or services may be discussed in this article.

\section{Competing interests}

All authors declare that they have no competing interests.

\section{Acknowledgements}

We wish to thank Ingrid Van Overbeke, Maria Olieslagers and Deborah Croes for their technical help during the experimental procedures and for taking care of the animals.

\section{Compliance with ethical standards}

This work was supported by a grant from "Le fond pour la chirurgie cardiaque". This work does not contain any studies with human participants performed by any of the authors. The study protocol was performed according to the standards of "The Guide for the Care and Use of Laboratory Animals" published by the National Institutes of Health (publication 85-23, revised 1996) and approved by the ethical committee for animal research of the Ghent University Hospital (ECD 18/30).

\section{Abbreviations}

DC, Distensibility coefficient; DPAP, Diastolic pulmonary artery pressure; MPAP, Mean pulmonary artery pressure; LAP, Left atrial pressure; PA, Pulmonary artery; R, Resistance; SPAP, Systolic pulmonary artery pressure. 


\section{References}

AL-TINAWI A, MADDEN JA, DAWSON CA, LINEHAN JH, HARDER DR, RICKABY DA: Distensibility of small arteries of the dog lung. J Appl Physiol 71: 1714-1722, 1991.

ARGIENTO P, VANDERPOOL RR, MULÈ M, RUSSO MG, D'ALTO M, BOSSONE E, CHESLER NC, NAEIJE R: Exercise stress echocardiography of the pulmonary circulation: limits of normal and sex differences. Chest 142: 1158-1165, 2012.

CAVALCANTE JL, LIMA JAC, REDHEUIL A, AL-MALLAH MH: Aortic stiffness: current understanding and future directions. J Am Coll Cardiol 57: 1511-1522, 2011.

DAWSON CA, KRENZ GS, KARAU KL, HAWORTH ST, HANGER CC, LINEHAN JH: Structure-function relationships in the pulmonary arterial tree. J Appl Physiol 86: 569-583, 1999a.

DAWSON CA, KRENZ GS, KARAU KL, HAWORTH ST, HANGER CC, LINEHAN JH: Structure-function relationships in the pulmonary arterial tree. J Appl Physiol 86: 569-583, 1999 b.

GREENWALD SE, BERRY CL, HAWORTH SG: Changes in the distensibility of the intrapulmonary arteries in the normal newborn and growing pig. Cardiovasc Res16: 716-725, 1982.

HERVE P, MUSSET D, SIMONNEAU G, WAGNER W, DUROUX P: Almitrine decreases the distensibility of the large pulmonary arteries in man. Chest 96: 572-577, 1989.

KRENZ GS, DAWSON CA: Vessel distensibility and flow distribution in vascular trees. J Math Biol 44: 360-374, 2002.

KRENZ GS, DAWSON CA: Flow and pressure distributions in vascular networks consisting of distensible vessels. Am J Physiol Heart Circ Physiol 284: H2192-H2203, 2003.

LAU EMT, CHEMLA D, GODINAS L, ZHU K, SITBON O, SAVALE L, MONTANI D, JAÏS X, CELERMAJER DS, SIMONNEAU G, HUMBERT M, HERVE P: Loss of vascular distensibility during exercise is an early hemodynamic marker of pulmonary vascular disease. Chest 149: 353-361, 2016.

LINEHAN JH, DAWSON CA, RICKABY DA: Distribution of vascular resistance and compliance in a dog lung lobe. J Appl Physiol Respir Environ Exerc Physiol 53: 158-168, 1982.

LINEHAN JH, HAWORTH ST, NELIN LD, KRENZ GS, DAWSON CA: A simple distensible vessel model for interpreting pulmonary vascular pressure-flow curves. J Appl Physiol 73: 987-994, 1992.

MALHOTRA R, DHAKAL BP, EISMAN AS, PAPPAGIANOPOULOS PP, DRESS A, WEINER RB, BAGGISH AL, SEMIGRAN MJ, LEWIS GD: Pulmonary vascular distensibility predicts pulmonary hypertension severity, exercise capacity, and survival in heart failure. Circ Heart Fail 9: e003011, 2016.

MÉLOT C, DELCROIX M, CLOSSET J, VANDERHOEFT P, LEJEUNE P, LEEMAN M, NAEIJE R: Starling resistor vs. distensible vessel models for embolic pulmonary hypertension. Am J Physiol 268: H817-H827, 1995.

MITZNER WA: Resistance of the pulmonary circulation. Clin Chest Med 4: 127-137, 1983.

NAEIJE R: Pulmonary vascular resistance. A meaningless variable? Intensive Care Med 29: 526-529, 2003.

PERMUTT S, RILEY RL: Hemodymics of collapsible vessels with tone: the vascular waterfall. J Appl Physiol 18: 924-932, 1963.

PRESSON RG, AUDI SH, HANGER CC, ZENK GM, SIDNER RA, LINEHAN JH, WAGNER WW, DAWSON CA: Anatomic distribution of pulmonary vascular compliance. J Appl Physiol 84: 303-310, 1998.

REEVES JT: Distensibility of the normal human lung circulation during exercise. Am J Physiol: Lung Cellular and Molecular Physiology 288: L419-L425, 2005.

SANZ J, KARIISA M, DELLEGROTTAGLIE S, PRAT-GONZÁlEZ S, GARCIA MJ, FUSTER V, RAJAGOPALAN S: Evaluation of pulmonary artery stiffness in pulmonary hypertension with cardiac magnetic resonance. JACC Cardiovasc Imaging 2: 286-295, 2009.

SCHÄFER M, MYERS C, BROWN RD, FRID MG, TAN W, HUNTER KS, STENMARK KR: Pulmonary arterial stiffness: toward a new paradigm in pulmonary arterial hypertension pathophysiology and assessment. Curr Hypertens Rep 18: 4, 2016. 
SEZAI A, SHIONO M, ORIME Y, NAKATA K, HATA M, IIDA M, KASHIWAZAKI S, KINOSHITA J, NEMOTO M, KOUJIMA T, FURUICHI M, EDA K, HIROSE H, YOSHINO T, SAITOH A, TANIGUCHI Y, SEZAI Y: Major organ function under mechanical support: comparative studies of pulsatile and nonpulsatile circulation. Artif Organs 23: 280-285, 1999.

STEVENS GR, GARCIA-ALVAREZ A, SAHNI S, GARCIA MJ, FUSTER V, SANZ J: RV Dysfunction in pulmonary hypertension is independently related to pulmonary artery stiffness. JACC Cardiovasc Imaging $\mathbf{5}$ : 378-387, 2012.

TAN W, MADHAVAN K, HUNTER KS, PARK D, STENMARK KR: Vascular stiffening in pulmonary hypertension: cause or consequence? Pulm Circ 4: 560-580, 2014.

WAUTERS A, VICENZI M, DE BECKER B, RIGA J-P, ESMAEILZADEH F, FAORO V, VACHIERY JL, VAN DE BORNE P, ARGACHA J-F: At high cardiac output, diesel exhaust exposure increases pulmonary vascular resistance and decreases distensibility of pulmonary resistive vessels. Am J Physiol: Heart and Circulatory Physiology 309: H2137-H2144, 2015.

WEST JB: State of the art: ventilation-perfusion relationships. Am Rev Respir Dis 116: 919-943, 1977. 